\title{
Safety and durability of mitral valve repair for anterior leaflet perforation
}

\author{
Basar Sareyyupoglu, MD, ${ }^{a}$ Hartzell V. Schaff, MD, ${ }^{\text {a }}$ Rakesh M. Suri, MD, DPhil, ${ }^{\text {a Heidi M. Connolly MD, }}{ }^{\text {b }}$ \\ Richard C. Daly, MD, and Thomas A. Orszulak, MD ${ }^{\mathrm{a}}$
}

Objective: We sought to evaluate mitral valve repair for anterior leaflet perforation.

\begin{abstract}
Methods: Between October 1987 and October 2006, 26 patients with mitral valve anterior leaflet perforation underwent mitral valve repair (median age, 54 years; 18 [69\%] were male).

Results: The indication for operation was severe mitral regurgitation only in 14 patients, both aortic regurgitation and mitral regurgitation in 11 , and ventricular septal defect repair in 1 . Twenty-four $(92 \%)$ patients had endocarditis and $13(50 \%)$ had at least mild aortic regurgitation preoperatively. Left atriotomy was performed in 17 $(65 \%)$ and aortotomy in $8(31 \%)$. Six $(23 \%)$ patients had visible vegetations at the time of repair. For anterior leaflet repair, a patch was used in $11(42 \%)$ patients and primary suture closure in $15(58 \%)$. Eighteen patients underwent concomitant cardiac surgical procedures. Postoperative follow-up (mean, 6 years) was available for 25 $(96 \%)$ patients. There was 1 early death from multiorgan failure and 2 late deaths. Patient survival was $95 \%$ at 1 year and $90 \%$ at 5 years. Left ventricular end-diastolic dimension improved significantly after mitral valve repair at dismissal $(\mathrm{n}=16 ;-9.4 \mathrm{~mm} ; P<.01)$ and during follow-up $(\mathrm{n}=11 ;-10.8 \mathrm{~mm} ; P<.01)$. Only $1(4 \%)$ patient had mitral valve reoperation after 7 years owing to recurrent endocarditis 6 months after repair.
\end{abstract}

Conclusions: Mitral valve anterior leaflet perforation may be safely repaired with good midterm survival and durability. (J Thorac Cardiovasc Surg 2010;139:1488-93)

Mitral valve repair for degenerative leaflet prolapse restores patient survival to normal, and contemporary repair techniques have excellent long-term durability. Indeed, freedom from reoperation is statistically indistinguishable between patients who undergo repair of posterior leaflet prolapse and patients who undergo mechanical valve replacement in the current era. Patients without atrial fibrillation who undergo successful mitral valve repair may return to normal activities without the need for systemic anticoagulation. ${ }^{1,2}$

Mitral regurgitation resulting from a diseased anterior leaflet is less common than mitral regurgitation caused by a diseased posterior leaflet. Several methods have been proposed for repair of anterior leaflet prolapse owing to chordal rupture or elongation. In addition to leaflet prolapse, anterior leaflet perforation resulting from endocarditis may lead to severe valve leakage. ${ }^{3,4}$ However, the techniques for repair of anterior leaflet perforation and late outcomes of repair are not widely known. We studied patients who had anterior mitral leaflet perforation to analyze their presentation, the

From the Division of Cardiovascular Surgery ${ }^{\mathrm{a}}$ and the Division of Cardiovascular Diseases, ${ }^{\mathrm{b}}$ Mayo Clinic, Rochester, Minn.

Disclosures: None.

Received for publication April 1, 2009; revisions received June 18, 2009; accepted for publication July 16, 2009; available ahead of print Sept 14, 2009.

Address for reprints: Rakesh M. Suri, MD, DPhil, Division of Cardiovascular Diseases, Mayo Clinic, 200 First St SW, Rochester, MN 55905 (E-mail: suri. rakesh@mayo.edu).

0022-5223/\$36.00

Copyright (c) 2010 by The American Association for Thoracic Surgery doi:10.1016/j.jtcvs.2009.07.040 surgical techniques used in repair, and the long-term outcomes of surgical repair.

\section{PATIENTS AND METHODS}

Between October 1987 and October 2006, 26 patients with perforation of the anterior leaflet of the mitral valve underwent mitral valve repair at Mayo Clinic, Rochester, Minnesota. The patients' ages ranged from 15 to 77 years (median, 54 years), and 18 (69\%) were male. The Mayo Clinic Institutional Review Board approved this study, and each patient in the study gave research authorization to be involved in clinical research.

Prior endocarditis was documented in $92 \%$ of the patients; 6 patients had acute endocarditis at the time of repair and had positive blood cultures and vegetations on the mitral valve. Fourteen patients had severe mitral regurgitation only, 4 patients had severe mitral regurgitation and severe aortic regurgitation, and 7 patients had severe aortic regurgitation and moderately severe mitral regurgitation. One patient had elective surgery for residual ventricular septal defect repair.

\section{Statistical Methods}

Descriptive statistics for categorical variables are reported as frequency and percentage; continuous variables are reported as mean $( \pm$ standard deviation) or median (range) as appropriate. Changes in continuous variables between preoperative and dismissal values were compared with the paired $t$ test or Wilcoxon rank sum test as appropriate. The Kaplan-Meier method was used to estimate 1-year and 5-year survival statistics.

\section{RESULTS \\ Operative Findings}

Surgical findings related to the mitral valve are presented in Table 1. All patients had at least 1 perforation on the anterior leaflet of the mitral valve. The size of the perforations varied from $0.25 \mathrm{~cm}^{2}$ to $4.0 \mathrm{~cm}^{2}$. Additional findings included chordal rupture in 7 patients and vegetations in 6 patients. 
TABLE 1. Mitral valve findings at the time of repair

\begin{tabular}{lrc}
\hline & \multicolumn{2}{c}{ Patients $(\mathbf{n}=\mathbf{2 6})$} \\
\cline { 2 - 3 } \multicolumn{1}{c}{ Lesion } & No. & $\%$ \\
\hline Chordal ruptures & 7 & 27 \\
$\quad$ Anterior leaflet & 3 & 12 \\
Posterior leaflet & 4 & 15 \\
Perforation & & \\
$\quad$ Anterior leaflet & 26 & 100 \\
$\quad$ Posterior leaflet & 1 & 4 \\
Vegetations & 6 & 23 \\
Ulcerated lesions & 18 & 69 \\
Subannular abscess & 1 & 4 \\
\hline
\end{tabular}

Aortic valve lesions are summarized in Table 2. Thirteen $(50 \%)$ patients had some degree of aortic regurgitation preoperatively. Eleven $(42 \%)$ patients had moderately severe or severe aortic regurgitation that necessitated surgical intervention on the aortic valve at the time of mitral valve repair. One patient with severe recurrent aortic regurgitation after 2 previous aortic valve replacements had a healed subannular abscess beneath the left coronary ostium. Another patient had vegetations on the noncoronary cusp that also caused an adjacent "kissing" lesion on the mitral anterior leaflet.

\section{Operative Technique}

Surgical techniques used for mitral valve repair are presented in Table 3.

Small defects of the anterior mitral leaflet were closed primarily with $4-0$ or 5-0 Prolene polypropylene suture (Ethicon Endo-Surgery, Inc, Cincinnati, Ohio). Larger defects were closed with either pericardial or synthetic patches (Table 4 and Figure 1). The patch used in the repair of anterior leaflet perforations was autologous in 6 patients, polytetrafluoroethylene (Gore-Tex; W. L. Gore \& Associates, Inc; Newark, Del) in 4, and bovine in 1.

\section{Associated Procedures}

Four patients underwent concomitant coronary artery bypass grafting at the time of repair of anterior leaflet perforation. Ten patients had concomitant aortic valve replacement, and 1 had aortic valve repair. An extended left ventricular

TABLE 2. Summary of aortic valve lesions

\begin{tabular}{lcc}
\hline \multicolumn{1}{c}{ Lesion } & \multicolumn{2}{c}{ Patients $(\mathbf{n}=\mathbf{2 6})$} \\
\cline { 2 - 3 } & No. & $\%$ \\
\hline Grade 3 or 4 aortic regurgitation & 11 & 42 \\
Mechanism of aortic regurgitation & & \\
$\quad$ Native aortic cusp perforation and vegetations & 5 & 19 \\
Prosthetic valve endocarditis and degeneration & 4 & 15 \\
Perivalvular leak & 1 & 4 \\
Valve degeneration & 1 & 4 \\
Subannular abscess & 1 & 4 \\
\hline
\end{tabular}

TABLE 3. Surgical technique used for mitral valve repair

\begin{tabular}{lrr}
\hline \multicolumn{1}{c}{ Lesion } & \multicolumn{2}{c}{ Patients $(\mathbf{n}=\mathbf{2 6})$} \\
\cline { 2 - 3 } & No. & $\%$ \\
\hline Surgical approach to mitral valve & & \\
$\quad$ Left atriotomy & 17 & 65 \\
Aortotomy & 8 & 31 \\
Interatrial septum & 1 & 4 \\
Perforation repair & & \\
Primary suture repair & 15 & 58 \\
Patch repair & 11 & 42 \\
$\quad$ Pericardial patch & 7 & 27 \\
$\quad$ Artificial patch & 4 & 15 \\
Mitral valve repair technique & & \\
Anterior leaflet resection & 3 & 12 \\
Posterior leaflet resection & 4 & 15 \\
Anterior artificial chordae placement & 3 & 12 \\
Posterior annuloplasty & 16 & 62 \\
Kay annuloplasty & 2 & 8 \\
Edge-to-edge repair & 1 & 4 \\
\hline
\end{tabular}

septal myectomy was performed in 2 patients. One patient had a left-sided maze procedure.

\section{Complications}

One patient underwent exploratory surgery for bleeding. There were no neurologic complications. There was 1 early death 29 days postoperatively from ongoing sepsis and multiorgan failure in a patient whose operation occurred during the acute phase of prosthetic valve endocarditis.

\section{Early Results}

All survivors had symptomatic improvement. The mean ( \pm standard deviation) hospital stay was $7.0 \pm 2.5$ days. Postoperative transthoracic echocardiograms showed that mitral regurgitation was absent in 15 patients, mild in 9 , and moderate in 2.

The repair technique for the patients with moderate mitral regurgitation at discharge was analyzed. In 1 patient, a large patch was placed without an annuloplasty band. The other patient had active endocarditis. After débridement, the anterior leaflet perforation was reconstructed primarily and a prosthetic annuloplasty band was therefore avoided to minimize foreign material. In both patients, the mechanism of recurrent mitral regurgitation was central.

TABLE 4. Repair according to perforation size

\begin{tabular}{lccccc}
\hline & \multicolumn{2}{c}{ Primary closure } & & \multicolumn{2}{c}{ Patch closure } \\
\cline { 2 - 3 } \cline { 6 - 7 } \multicolumn{1}{c}{ Defect size* } & No. & $\%$ & & No. & $\%$ \\
\hline Small $\left(0.25-0.75 \mathrm{~cm}^{2}\right)$ & 8 & 80 & & 2 & 20 \\
Moderate $\left(>0.75-1.5 \mathrm{~cm}^{2}\right)$ & 2 & 50 & & 2 & 50 \\
Large $\left(>1.5-4.0 \mathrm{~cm}^{2}\right)$ & 0 & 0 & & 7 & 100 \\
\hline *Size was defined by surgical inspection only. & & &
\end{tabular}



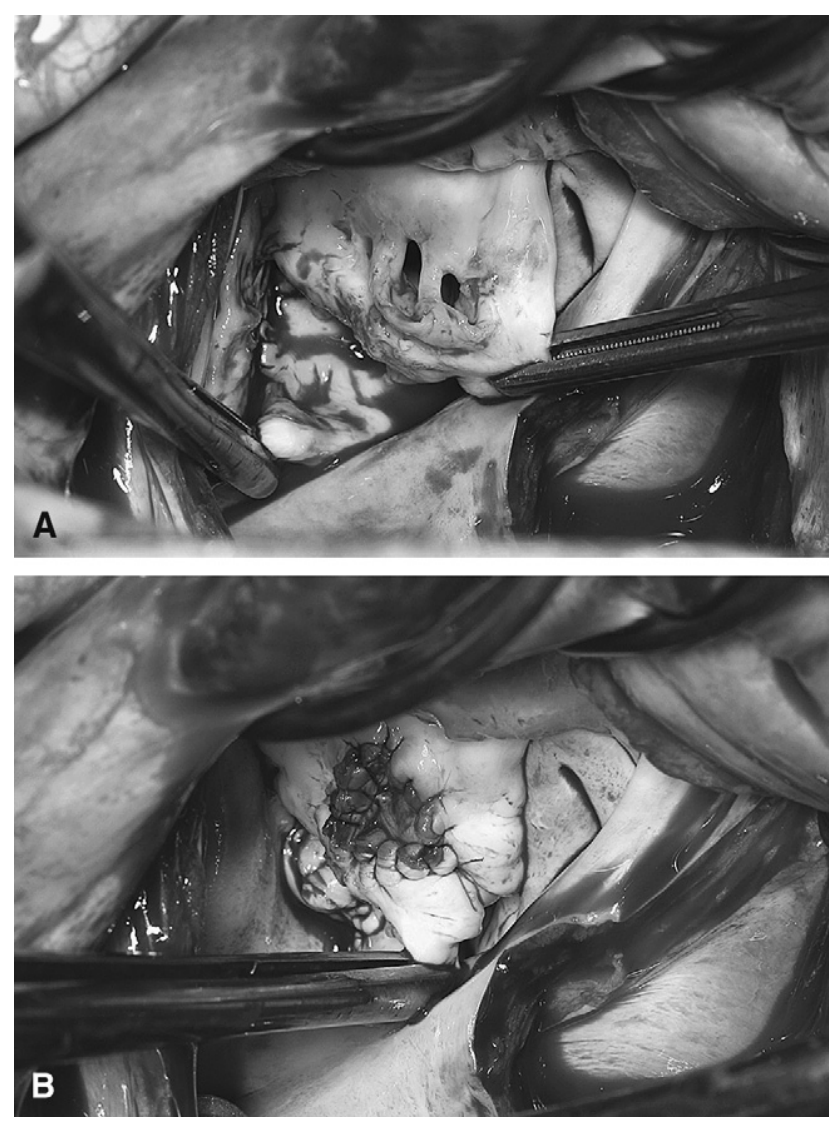

FIGURE 1. Patch repair of mitral valve anterior leaflet perforation through left atriotomy.

\section{Late Follow-up}

Late follow-up findings were available for 24 of the 25 late survivors. There were 2 late deaths: 1 patient died of congestive heart failure 11 years postoperatively but had normal mitral valve function at an earlier echocardiogram, and another patient died of unknown causes 3 years postoperatively. Mean follow-up was 6 years. Overall patient survival was $95 \%$ at 1 year and $90 \%$ at 5 years.

Long-term echocardiographic follow-up showed that mitral regurgitation was absent in 6 patients, mild in 6 , and moderate in 1 who was in clinically stable condition. Recurrent severe mitral regurgitation was observed in only 1 patient $(7 \% ; n=14)$. In that patient, recurrent endocarditis developed 7 months after initial mitral valve repair and was managed medically. Six years later, the patient had mitral valve replacement owing to severe mitral regurgitation.

Left ventricular end-diastolic dimension significantly improved after mitral valve repair at dismissal $(\mathrm{n}=16 ;-9.4$ $\mathrm{mm} ; P<.01)$ and was maintained during follow-up $(\mathrm{n}=$ $11 ;-10.8 \mathrm{~mm} ; P<.01)$.

\section{DISCUSSION}

Early and late mortality and event-free survival are better among patients undergoing mitral valve repair for severe mi- tral regurgitation than among patients having mitral valve replacement. This is true for patients with degenerative valve disease and for patients with mitral valve endocarditis. Mitral valve repair should be carried out whenever possible in patients with endocarditis ${ }^{3-7}$ because late morbidity is low and valvuloplasty appears to have a lower risk of reinfection than prosthetic valve replacement. ${ }^{8,9}$ The present study shows that successful mitral valve repair to correct anterior mitral leaflet perforation is safe and durable.

Perforation of the valve leaflets is seen in as many as one third of all patients with mitral valve endocarditis, ${ }^{3,10}$ but few studies have evaluated results of surgical repair of anterior leaflet perforation. In prior publications, the largest cohort with perforations of the mitral valve leaflets included 21 patients, ${ }^{10}$ and the largest group with documented anterior leaflet perforation included 8 patients. ${ }^{4}$ In our series, all 26 patients had anterior mitral leaflet perforation, and all underwent valve repair with evaluation of the durability of the repair and assessment of patient survival and clinical status.

Comparison between patients undergoing mitral valve repair or replacement to treat endocarditis may be difficult because patients with severely damaged valves tend to undergo valve replacement. ${ }^{6}$ Even with large defects of the mitral valve anterior leaflet, valve repair is possible. In published studies, the feasibility of repairing infected mitral valves for acute endocarditis varies from $33 \%$ to $78 \%{ }^{6,10,11}$ The present study included only patients who had valve repair; therefore, the frequency of repair versus replacement could not be calculated. However, a repair rate of approximately $30 \%$ to $50 \%$ is consistent with our experience in managing mitral valve endocarditis. We would not recommend a repair attempt if clinical factors suggested that a complex mitral valve reconstruction would not be in the patient's best interest. Poor leaflet tissue quality or severe tissue destruction would also suggest that repair durability would be limited.

In many patients the mechanism of injury to the mitral valve anterior leaflet is aortic valve regurgitation, with the regurgitant jet being directed toward the mitral valve anterior leaflet, eroding the tissue and leaving a surface more prone to infection (Figure 2). In our series, 13 patients had hemodynamically significant aortic valve regurgitation. A windsock deformity (Figures 3 and 4 ) of the mitral valve leaflet is often seen in association with anterior leaflet perforation. ${ }^{12-15} \mathrm{An}$ other pathologic mechanism for anterior leaflet perforation may be "kissing" lesions between vegetations on 1 or more aortic valve cusps and the mitral valve anterior leaflet, allowing migration of infection to the mitral valve. ${ }^{14,15}$

In our series of 26 patients, repair was successful for anterior leaflet defects even in patients with acute or subacute endocarditis. We tended to patch large defects with autologous pericardium or polytetrafluoroethylene. For acute or subacute infections, we prefer autologous material to minimize the risk of reinfection. Smaller defects were repaired 


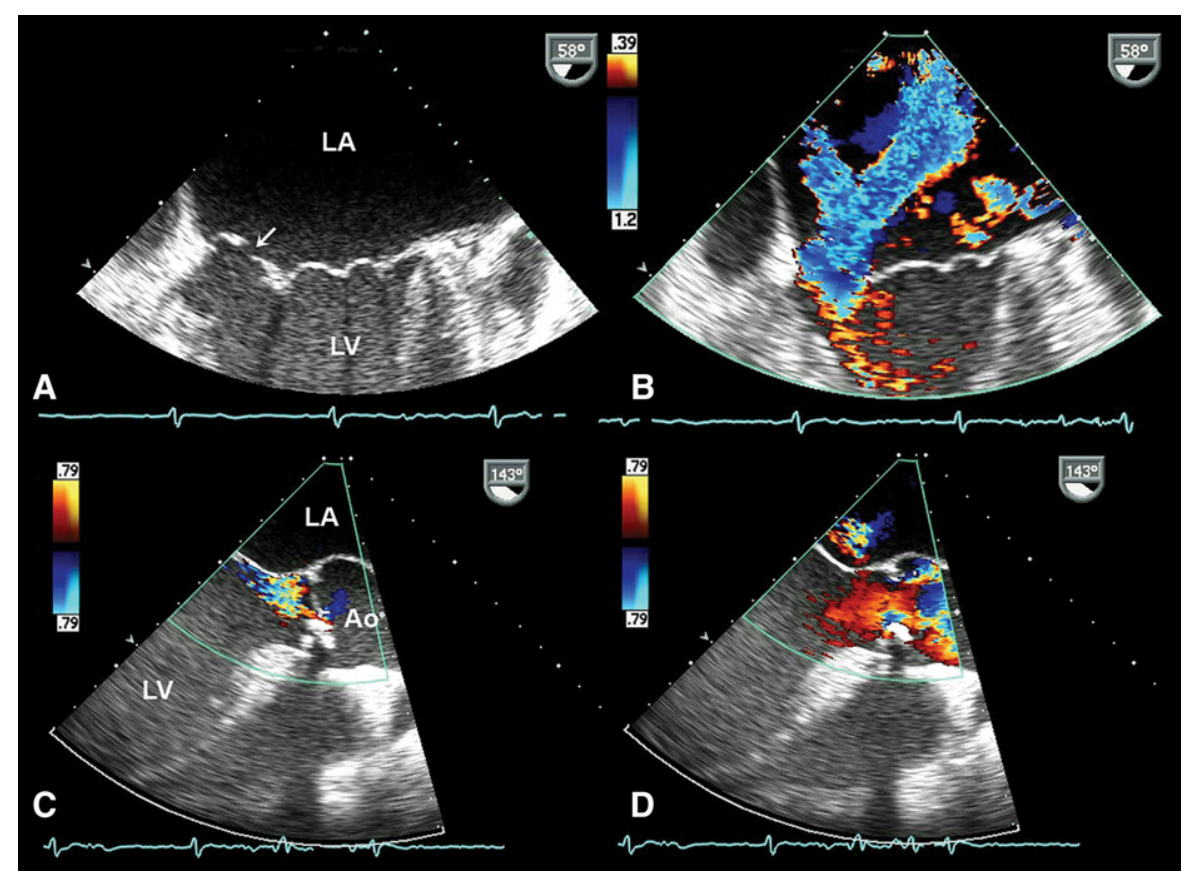

FIGURE 2. Mitral valve anterior leaflet perforation. A, Transesophageal echocardiographic image shows a mitral valve anterior leaflet perforation (arrow). $\mathrm{B}$, The resultant eccentric mitral valve regurgitation is apparent with color flow imaging. $\mathrm{C}$, The mitral valve anterior leaflet perforation was thought to be due to aortic valve vegetations and the eccentric aortic valve regurgitant jet (diastolic frame) hitting the mitral valve anterior leaflet. D, The result was eccentric mitral valve regurgitation (systolic frame). Ao, Aorta; $L A$, left atrium; $L V$, left ventricle.

primarily; the important technical aspect is to avoid distortion of the anterior leaflet. The only patient in this series who required late reoperation had recurrent endocarditis, but the patient did not have active endocarditis or an artificial patch during the first repair.

Sometimes defects of mitral valve leaflets may not be visualized well with transthoracic echocardiography, and the surgeon may not request intraoperative transesophageal echocardiography for aortic valve procedures. Thus, it is especially important to examine the mitral valve anterior leaflet in cases of aortic valve endocarditis. Both diagnosis and surgical repair may be performed through the aortic root (Figure 4). ${ }^{16-19}$ We repaired the anterior leaflet perforation through the aortic annulus in 8 patients in this series. Interestingly, 1 of these patients had an initial left atriotomy, but anterior leaflet repair was performed through the aortotomy because exposure was better.

An important decision in the repair of anterior leaflet perforations is whether to perform a concomitant annuloplasty. In contrast to valve repair for degenerative mitral regurgitation in which ventricular enlargement and annular dilatation are the rule, patients with anterior leaflet perforation resulting from endocarditis may present earlier in the course of the disease because of infection or aortic valve leakage (or both). In these patients who have little mitral annular dilatation and good leaflet coaptation, annuloplasty is not necessary, as was true in 10 patients in this series. In the remaining patients $(62 \%)$, we performed annuloplasty to decrease the annular size and to improve apposition of the anterior and posterior mitral valve leaflets.

Symptomatic improvement soon after correction of severe mitral valve regurgitation is thought to correlate with ventricular remodeling. ${ }^{20} \mathrm{We}$ also noted regression of the end-diastolic ventricular dimension after repair of anterior leaflet perforation, but some of this improvement may have been due to correction of associated aortic valve regurgitation.

Mitral valve replacement carries the burden of prosthetic valve-related complications. ${ }^{21,22}$ This may be particularly true in younger patients who will carry the risk longer. The choice of a mechanical mitral prosthesis presents additional risks of bleeding owing to long-term anticoagulation with warfarin. ${ }^{22,23}$ Use of a tissue prosthesis imposes the risk of valve deterioration: up to $31 \%$ at 10 years and $68 \%$ at 15 years. ${ }^{21}$ Both options carry the risk of prosthetic endocarditis. ${ }^{9}$ The most important preoperative predictor of prosthetic valve endocarditis was active endocarditis at operation. ${ }^{9}$ Operative mortality was reported to be $14 \%$ to $18 \%$ with valve replacement in the treatment of endocarditis. ${ }^{3,8}$ The frequency of late recurrent endocarditis was reported to be $7 \%$ to $14 \%$ for mitral valve replacement in endocarditis ${ }^{3,8}$ and $2 \%$ for mitral valve repair. ${ }^{3}$ In the present study, we observed recurrent endocarditis in only $1(4 \%)$ patient. 


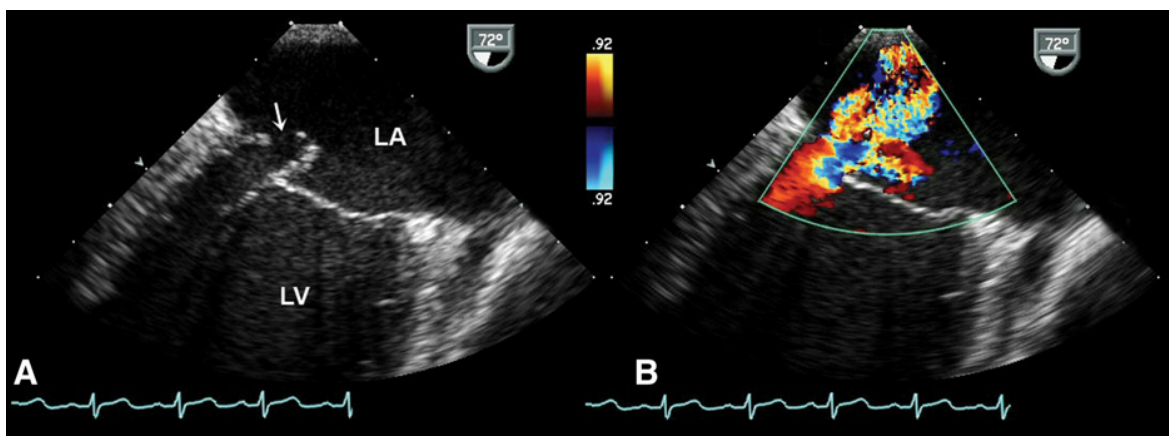

FIGURE 3. Windsock deformity. A, Transesophageal echocardiographic image demonstrates a mitral valve anterior leaflet perforation with a windsock deformity (arrow). B, Color flow imaging shows the resultant eccentric mitral valve regurgitation. LA, Left atrium; LV, left ventricle.

\section{Limitations}

This is a small retrospective review, and as such it is influenced by typical biases. The decision of whether to repair or replace the mitral valve in the setting of leaflet perforation owing to endocarditis was influenced by the stability of the patient's condition, comorbidities, and concomitant procedures. This article provides a technical description of the features and outcomes of anterior leaflet mitral perforations
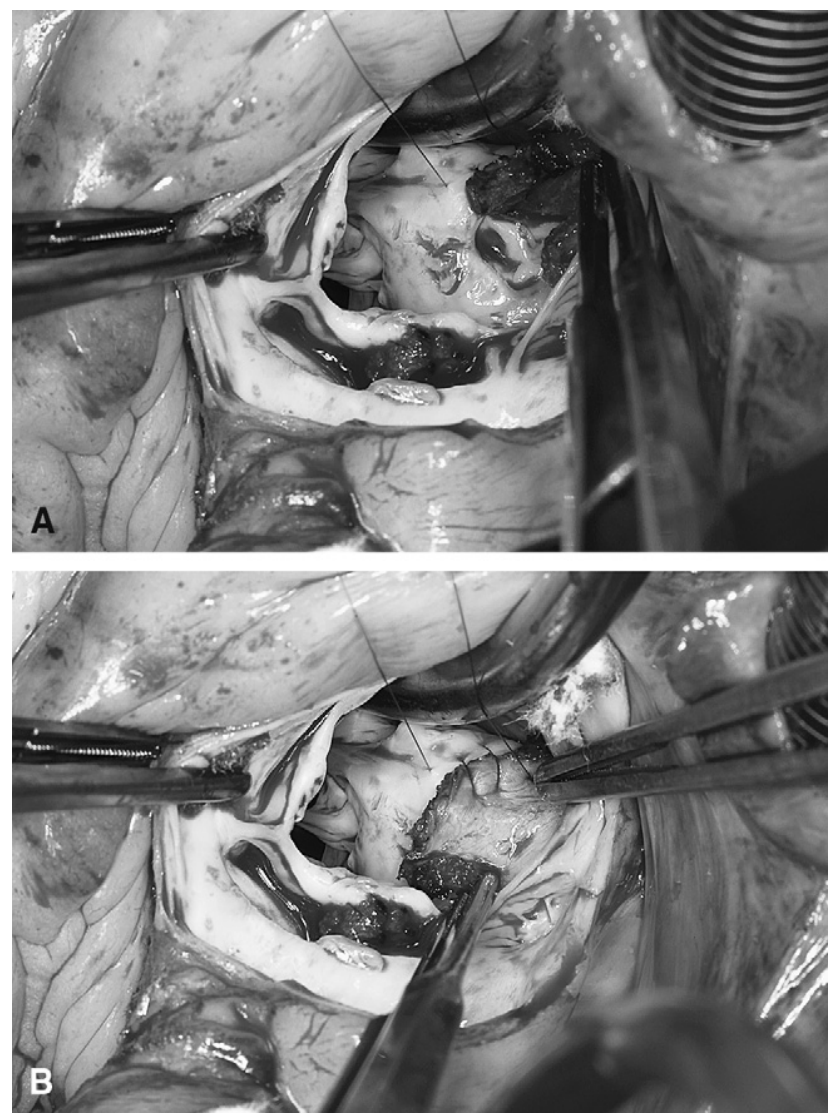

FIGURE 4. Repair of mitral valve anterior leaflet windsock deformity. A pericardial patch is placed through the left ventricular outflow tract in a patient undergoing concomitant aortic valve repair for severe aortic regurgitation after endocarditis has healed. deemed appropriate for leaflet repair by the surgeon. The duration and frequency of echocardiographic follow-up is admittedly heterogeneous, inasmuch as it was limited by the availability of follow-up longitudinal imaging in clinically stable patients.

\section{CONCLUSION}

Mitral valve anterior leaflet perforation is often associated with endocarditis and aortic valve regurgitation. Perforations in the anterior leaflet may be the only mechanism of mitral regurgitation. Large defects may cause severe heart failure and warrant surgical attention whenever they are diagnosed. Repair of anterior leaflet perforation is a relatively simple but effective way to correct mitral regurgitation and achieve durable results.

\section{References}

1. Suri RM, Schaff HV, Dearani JA, Sundt TM 3rd, Daly RC, Mullany CJ, et al. Survival advantage and improved durability of mitral repair for leaflet prolapse subsets in the current era. Ann Thorac Surg. 2006;82:819-26.

2. Mohty D, Orszulak TA, Schaff HV, Avierinos JF, Tajik JA, Enriquez-Sarano M. Very long-term survival and durability of mitral valve repair for mitral valve prolapse. Circulation. 2001;104(12 Suppl. 1):I1-7.

3. Feringa HH, Shaw LJ, Poldermans D, Hoeks S, van der Wall EE, Dion RA, et al. Mitral valve repair and replacement in endocarditis: a systematic review of literature. Ann Thorac Surg. 2007;83:564-70.

4. Dreyfus G, Serraf A, Jebara VA, Deloche A, Chauvaud S, Couetil JP, et al. Valve repair in acute endocarditis. Ann Thorac Surg. 1990;49:706-11.

5. Hendren WG, Morris AS, Rosenkranz ER, Lytle BW, Taylor PC, Stewart WJ, et al. Mitral valve repair for bacterial endocarditis. J Thorac Cardiovasc Surg. 1992;103:124-8.

6. Sternik L, Zehr KJ, Orszulak TA, Mullany CJ, Daly RC, Schaff HV. The advantage of repair of mitral valve in acute endocarditis. J Heart Valve Dis. 2002;11: 91-7.

7. Wilhelm MJ, Tavakoli R, Schneeberger K, Horstrupp S, Reuthebuch O, Seifert B, et al. Surgical treatment of infective mitral valve endocarditis. J Heart Valve Dis. 2004;13:754-9.

8. Moon MR, Miller DC, Moore KA, Oyer PE, Mitchell RS, Robbins RC, et al. Treatment of endocarditis with valve replacement: the question of tissue versus mechanical prosthesis. Ann Thorac Surg. 2001;71:1164-71.

9. Grover FL, Cohen DJ, Oprian C, Henderson WG, Sethi G, Hammermeister KE. Determinants of the occurrence of and survival from prosthetic valve endocarditis: experience of the Veterans Affairs Cooperative Study on Valvular Heart Disease. J Thorac Cardiovasc Surg. 1994;108:207-14.

10. Iung B, Rousseau-Paziaud J, Cormier B, Garbarz E, Fondard O, Brochet E, et al. Contemporary results of mitral valve repair for infective endocarditis. J Am Coll Cardiol. 2004;43:386-92. 
11. Mihaljevic T, Paul S, Leacche M, Rawn JD, Aranki S, O'Gara PT, et al. Tailored surgical therapy for acute native mitral valve endocarditis. $J$ Heart Valve Dis. 2004; 13:210-6.

12. Paruchuru PK, Adluri K, Patel RL. Windsock deformity of the mitral valve: a late presentation of endocarditis. Eur J Cardiothorac Surg. 2002;21:88.

13. Rachko M, Safi AM, Yeshou D, Salciccioli L, Stein RA. Anterior mitral valve aneurysm: a subaortic complication of aortic valve endocarditis: a case report and review of literature. Heart Dis. 2001;3:145-7.

14. Vilacosta I, San Roman JA, Sarria C, Iturralde E, Graupner C, Batlle E, et al. Clinical, anatomic, and echocardiographic characteristics of aneurysms of the mitral valve. Am J Cardiol. 1999;84:110-3, A9.

15. Halkos ME, Symbas JD, Felner JM, Symbas PN. Aneurysm of the mitral valve: a rare complication of aortic valve endocarditis. Ann Thorac Surg. 2004;78:e65-6.

16. Crawford ES, Coselli JS. Marfan's syndrome: combined composite valve graft replacement of the aortic root and transaortic mitral valve replacement. Ann Thorac Surg. 1988;45:296-302.

17. Najafi H, Hemp JR. Mitral valve replacement through the aortic root. J Thorac Cardiovasc Surg. 1994;107:1334-6.
18. Koizumi J, Nakajima T, Izumoto H, Ohsawa S, Ishihara K, Kawazoe K Transaortic mitral valve repair combined with a modified Bentall procedure in a patient with Marfan's syndrome: report of a case. Surg Today. 2004; 34:774-6.

19. Nakamura Y, Nakano K, Nakatani H, Sato A. Patch repair of mitral valve perforation with excised aortic valve cusp in patient with endocarditis. Eur J Cardiothorac Surg. 2006;30:673. Epub 2006 Aug 28.

20. Suri RM, Schaff HV, Dearani JA, Sundt TM 3rd, Daly RC, Mullany CJ, et al. Recovery of left ventricular function after surgical correction of mitral regurgitation due to leaflet prolapse. J Thorac Cardiovasc Surg. 2009;137:1071-6.

21. Potter DD, Sundt TM 3rd, Zehr KJ, Dearani JA, Daly RC, Mullany CJ, et al. Risk of repeat mitral valve replacement for failed mitral valve prostheses. Ann Thorac Surg. 2004;78:67-72

22. Edmunds LH Jr. Thrombotic and bleeding complications of prosthetic heart valves. Ann Thorac Surg. 1987;44:430-45.

23. Stein PD, Alpert JS, Bussey HI, Dalen JE, Turpie AG. Antithrombotic therapy in patients with mechanical and biological prosthetic heart valves. Chest. 2001 119(1 Suppl):220S-7S. Erratum in: Chest. 2001;120:1044. 